\title{
Thanatophoric dysplasia type 1 (TD1): a case report
}

\author{
Deepti Sharma $^{1 *}$, Chandra Madhur Sharma ${ }^{2}$
}

\author{
${ }^{1}$ Department of Obstetrics \& Gynaecology, Subharti Medical College, Meerut, U.P., India \\ ${ }^{2}$ Department of Paediatrics, Subharti Medical College, Meerut, U.P., India
}

Received: 10 September 2014

Accepted: 19 September 2014

\author{
*Correspondence: \\ Dr. Deepti Sharma, \\ E-mail: drdeeptisharma04@gmail.com
}

Copyright: ( ) the author(s), publisher and licensee Medip Academy. This is an open-access article distributed under the terms of the Creative Commons Attribution Non-Commercial License, which permits unrestricted non-commercial use, distribution, and reproduction in any medium, provided the original work is properly cited.

\begin{abstract}
Thanatophoric Dysplasia (TD) is a severe short-limb dwarfism syndrome that is usually lethal in the perinatal period. It is characterized by shortening of the limbs, severely small thorax, large head with a prominent forehead, macrocephaly, curved femur, and flattened vertebral bodies. Thanatophoric dysplasia is divided into 2 clinically defined subtypes: thanatophoric dysplasia type $1 \&$ type 2 (TD1 \& TD2). We report this case because of its rarity with review of literature.
\end{abstract}

Keywords: Skeletal dysplasia, FGFR3, Macrocephaly, Platyspondylia

\section{INTRODUCTION}

Thanatophoric Dysplasia (TD) is a type of neonatal lethal skeletal dysplasias. It was first described by Maroteaux and Lamy in $1967 .{ }^{1}$ It is the most common form of lethal congenital skeletal dysplasia with an incidence of 1 in 64000 to 1 in 100000 of the total live births. Males are affected more than females. It is of two major subtypes type 1 (TD1) \& type 2 (TD2). ${ }^{2}$ TD 1 , the more common subtype, is characterized by a normal-shaped skull and curved long bones (shaped like a telephone receiver). TD2 is associated with a cloverleaf-shaped skull and straight femurs. However, clinical overlap is observed between these subtypes. Other features of both types include; shortening of the limbs, severely small thorax, large head with a prominent forehead, macrocephaly and flattened vertebral bodies (platyspondyly). ${ }^{3} \mathrm{TD}$ is caused due to mutation of the Fibroblast Growth Factor Receptor 3 gene (FGFR3), which is located on the short arm of chromosome 4 . The mutation results in the activation of FGFR3 tyrosine kinase independently of ligands such as fibroblast growth factor 8. This activation of FGFR3 results in decreased apoptosis and increased proliferation. It was reported that hypochondroplasia, achondroplasia and thanatophoric dysplasia are the different types of mutation in FGFR3 with hypochondroplasia being the mildest and TD, the most severe form. ${ }^{3}$ Because of the rarity of this condition we report this case with review of the available literature.

\section{CASE REPORT}

A still born male baby was delivered by vaginal delivery at the gestational age of 37 weeks and 4 days. He was a product of non-consanguineous marriage. The baby's mother was a 21-year-old primigravida mother and did not undergo any antenatal evaluation. She was admitted to our hospital when her labor pains started. The prenatal two dimensional ultrasound examination just before the delivery showed polyhydramnios and short-limbed dwarfism. She had no history of drug, alcohol, or tobacco abuse in antenatal period. The baby's parents were healthy, and there was no family history of any congenital anomalies.

At the time of birth, the baby's heart rate and respiratory efforts were absent. General appearance was cyanotic blue colored. The body weight at birth was $2565 \mathrm{~g}$ (25$50^{\text {th }}$ percentile $)$ and length was $40.5 \mathrm{~cm}\left(<5^{\text {th }}\right.$ percentile $)$. The head circumference was $40.0 \mathrm{~cm}$ ( $>90^{\text {th }}$ percentile), 
the thoracic circumference was $27 \mathrm{~cm}$ and the abdominal circumference was $30 \mathrm{~cm}$. He had a large head with prominent forehead, excess skin over face, depressed nasal bridge with a short neck. He also had Narrow thorax, which was disproportionately small in relation to the abdomen, protuberant abdomen and very short limbs with small hands and brachydactyly (Figure 1). Based on above mentioned anomalies, diagnosis of TD type 1 was established. Parents have refused for the autopsy of the baby. After careful examination baby's dead body had been handover to the parents.

Counseling of the parents was done and explained them for the nature of TD and the recurrence risk is very low. Parents also counseled for the proper antenatal care and prenatal diagnostic tests. Written informed consent was taken from the parents for publication that included photograph also.

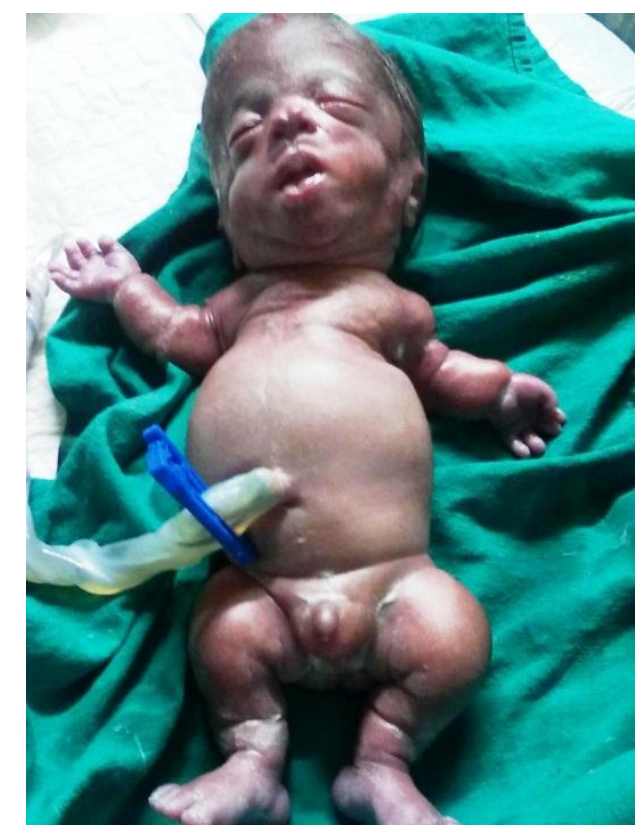

Figure 1: Thanatophoric dyplasia type 1 with all the classical features; macrocephaly, short neck, flat nasal bridge, boxer's face appearance, narrow bell shaped thorax (shape of a champagne bottle cork) with protuberant abdomen and small and curved long bone.

\section{DISCUSSION}

The term Thanatophoric Dysplasia (TD) originates from a Greek term for "death bearing". As the name suggests, the condition is frequently lethal in-utero or shortly after birth. TD is characterized by an abnormal head, face, thorax and skeleton. The head anomaly consists of megacephaly, occasionally with a cloverleaf-shaped skull. The term 'clover leaf skull' has been used synonymously to Kleeblattschlader syndrome. The premature closures of coronal and lambdoid sutures are commonly seen with the cloverleaf skull. ${ }^{3}$ In the face, excess skin usually yields a "boxer's face" appearance, with frontal bossing and a depressed nasal bridge. A hypoplastic thorax is common, which is disproportionately small in relation to the abdomen. Classically, a bell-shaped thorax has the shape of a champagne bottle cork and results in pulmonary hypoplasia. Ribs are hypoplastic, and the long bones of the extremities are short and curved, resulting in telephone receiver shaped femurs. Vertebrae are flattened with diminution of the intervertebral spaces. ${ }^{3}$

Based on bone deformity pattern, TD has been divided into two types. Type 1 is more common and is characterized by curved long bones (with a 'telephone receiver' appearance) and severe platyspondylia, usually without a cloverleaf skull. Our case belongs to type 1 TD. In type II, the long bones are relatively straight, the platyspondylia is less severe, and a cloverleaf skull is usually present. ${ }^{4}$ Affected individuals generally die within minutes or days after birth, usually from respiratory failure. Respiratory insufficiency may be secondary to the narrow chest cavity and hypoplastic lungs or due to cervical cord compression at a narrowed foramen magnum associated with posterior arch anomaly. ${ }^{5}$ There is no particularly predisposed population and recurrence risk is very low due to sporadic nature.

Thanatophoric dysplasia is considered an autosomal dominant disorder because one mutated copy of the FGFR3 gene in each cell is sufficient to cause the condition. Virtually all cases of thanatophoric dysplasia are caused by new mutations in the FGFR3 gene and occur in people with no history of the disorder in their family. No affected individuals are known to have had children; therefore, the disorder has not been passed to the next generation. This usually leads to death in-utero or shortly after birth of the fetus; the longest survival however has been reported to be of 9 years. ${ }^{6}$

Full term TD is less commonly seen in the modern obstetric era because of routine antenatal ultrasonography, but in our case mother never had any antenatal evaluation until just before the delivery. The diagnosis is usually suspected by antenatal ultrasonography examination and confirmed by molecular analysis on amniocytes. Antenatal ultrasonography in second trimester not only confirms the diagnosis but also differentiates it from the other nonlethal dysplasias. Three dimensional ultrasound is able to visualize the thickened redundant skin fold, limb and craniofacial anomalies more clearly. ${ }^{7}$ However, it is not always possible to differentiate TD from other skeletal dysplasias by ultrasonography alone; thus, molecular genetic analysis of the Fibroblast Growth Factor Receptor 3 (FGFR3) gene is useful for the prenatal diagnosis of TD. $^{7}$

In this disease counseling part is most important because most families who had a fetus with thanatophoric dysplasia would be too much apprehensive for further pregnancy. Since the majority of cases occur sporadically, it is important to counsel the family 
members that the recurrence risk is very low. ${ }^{8}$ To relieve parental anxiety in such low risk couple, prenatal sonography may be offered in subsequent pregnancies to identify features suggestive of TD. If indicated, amniocentesis and FGR3 analysis should be done to make a diagnosis.

\section{CONCLUSION}

Thus ours is a rare case of thanatophoric dyplasia type 1 with all the classical features that include macrocephaly, short neck, flat nasal bridge, boxer's face appearance, narrow bell shaped thorax (shape of a champagne bottle cork) with protuberant abdomen and small and curved long bones with small hands and brachydactyly. This case would give us a better understanding of this disorder. Early diagnosis can be made by antenatal sonography and FGR3 analysis. Most important aspect of the management is counselling of the parents.

Funding: No funding sources

Conflict of interest: None declared

Ethical approval: Not required

\section{REFERENCES}

1. Maroteaux P, Lamy M, Robert JM. Thanatophoric dwarfism. Presse Med. 1967;75:2519.
2. Chang TK, Wang Y, Liu AM, Tung JC. Thanatophoric dysplasia type 1. Acta Paediatr Taiwan. 2001;42(1):39-41.

3. Noe EJ, Yoo HW, Kim KN, Lee SY. A case of thanatophoric dysplasia type I with an R248C mutation in the FGFR3 gene. Korean $\mathrm{J}$ Paediatr. 2010;53(12):1022-5.

4. Langer LO Jr, Yang SS, Hall JG, Sommer A, Kottamasu SR, Golabi M, et al. Thanatophoric dysplasia and cloverleaf skull. Am J Med Genet Suppl. 1987;3:167-79.

5. Lam AC, Lam YY, Tong TM, Chan DK, Lau WL, $\mathrm{Ng}$ DK, et al. Thanatophoric dysplasia type 1 (TD1) without "telephone receivers". HK J Paediatr. 2006;11:320-3.

6. Baker KM, Olson DS, Harding CO, Pauli RM. Long term survival in typical thanatophoric dysplasia Type 1. Am J Med Genetics. 1997;70:427-36.

7. Wong HS, Kidd A, Zuccollo J, Tuohy J, Strand L, Tait J, et al. A case of thanatophoric dysplasia: the early prenatal 2D and 3D sonographic findings and molecular confirmation of diagnosis. Fetal Diagn Ther. 2008;24(1):71-3.

8. Naveen NS, Murlimanju BV, Kumar V, Pulakunta T, Jeeyar H. Thanatophoric dysplasia: a rare entity. Oman Med J. 2011;26(3):196-7.

DOI: $10.5455 / 2320-1770 . i j r \operatorname{cog} 20141253$

Cite this article as: Sharma D, Sharma CM.

Thanatophoric dysplasia type 1 (TD1): a case report. Int J Reprod Contracept Obstet Gynecol 2014;3:1127-9. 